
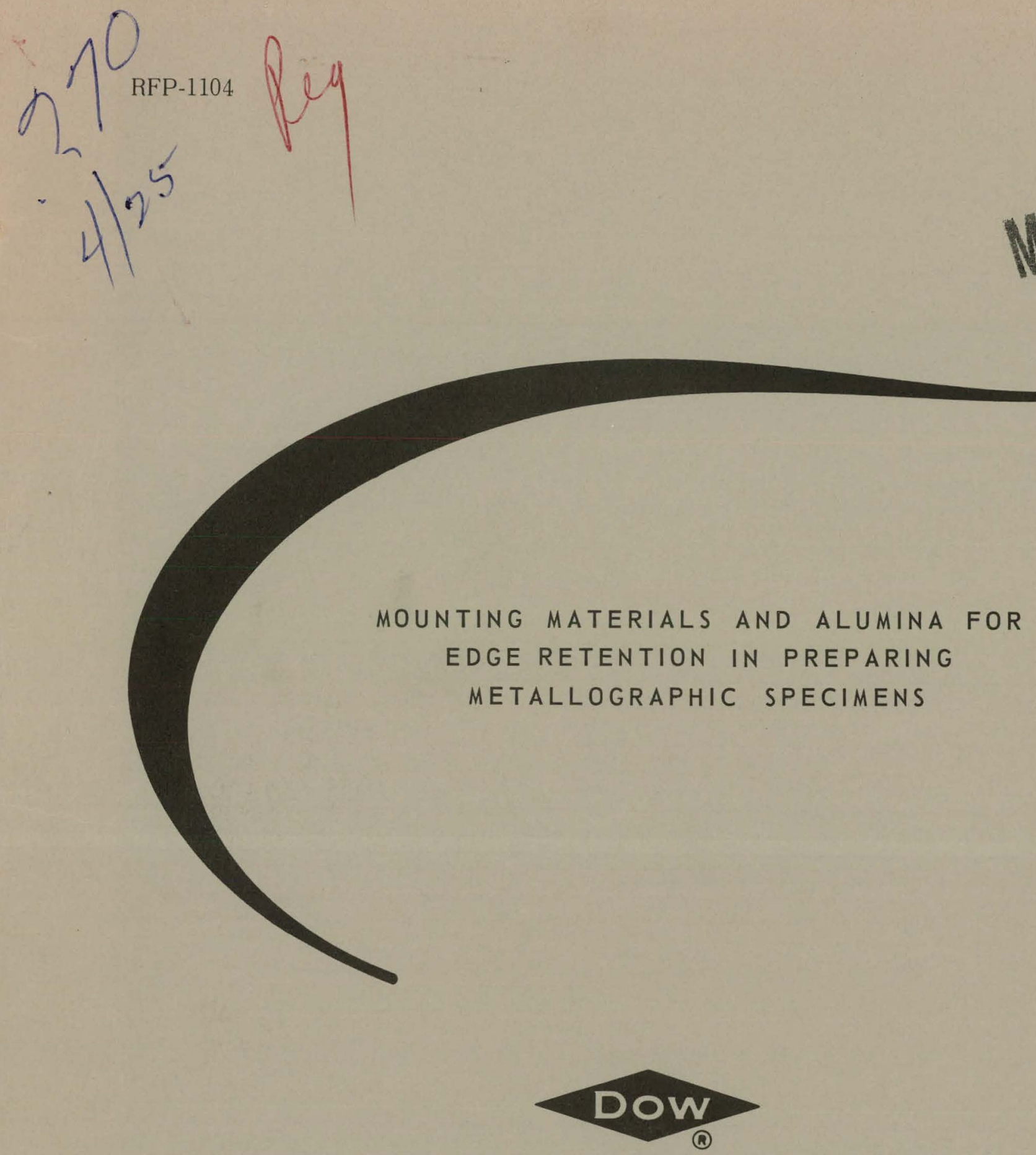

THE DOW CHEMICAL COMPANY ROCKY FLATS DIVISION

P. O. BOX 888

GOLDEN, COLORADO 80401

U.S. ATOMIC ENERGY COMMISSION CONTRACT AT(29-1)-1106 


\section{DISCLAIMER}

This report was prepared as an account of work sponsored by an agency of the United States Government. Neither the United States Government nor any agency Thereof, nor any of their employees, makes any warranty, express or implied, or assumes any legal liability or responsibility for the accuracy, completeness, or usefulness of any information, apparatus, product, or process disclosed, or represents that its use would not infringe privately owned rights. Reference herein to any specific commercial product, process, or service by trade name, trademark, manufacturer, or otherwise does not necessarily constitute or imply its endorsement, recommendation, or favoring by the United States Government or any agency thereof. The views and opinions of authors expressed herein do not necessarily state or reflect those of the United States Government or any agency thereof. 


\section{DISCLAIMER}

Portions of this document may be illegible in electronic image products. Images are produced from the best available original document. 


\section{LEG A L NOTICE}

This report was prepared as an account of Government sponsored work. Neither the United States, nor the Commission, nor any person acting on behalf of the Commission:

A. Makes any warranty or representation, expressed or implied, with respect to the accuracy, completeness, or usefulness of the information contained in this report, or that the use of any information, apparatus, method, or process disclosed in this report may not infringe privately owned rights; or

B. Assumes any liabilities with respect to the use of, or for damages resulting from the use of any information, apparatus, method, or process disclosed in this report.

As used in the above, "person acting on behalf of the Commission" includes any employee or contractor of the Commission, or employee of such contractor, to the extent that such employee or contractor of the Commission, or employee of such contractor prepares, disseminates, or provides access to, any information pursuant to his employment or contract with the Commission, or his employment with such contractor.

Printed in the United States of America

Available from

Clearinghouse for Federal Scientific and Technical Information National Bureau of Standards, U. S. Department of Commerce

Springfield, Virginia 22151

Price: Printed Copy $\$ 3.00$; Microfiche $\$ 0.65$ 


\section{MOUNTING MATERIALS AND ALUMINA FOR EDGE RETENTION IN PREPARING METALLOGRAPHIC SPECIMENS}

A. E. Calabra

\section{LEGAL NOTICE}

This report was prepared as an account of Government sponsored work. Nelther the United - States, nor the Commission, nor any person acting on behalf of the Commission:

A. Makes any warranty or representation, expressed or implied, with respect to the accuracy, completcncoo, or usefulness of the information contained in this report, or that the use of any information, apparatus, method, or process disclosed in thls cejurt niay not infringo privately owned rights; or B. Assumes any liabllitles with respect to the use of, or for damages resulting from the of any information, apparatus, method, or process disclosed in this report.

As used in the above. "person acting on behalf of the Commission" includes any employee or contractor of the Commission, or employee of such contractor, to the extent that such employee or contractor of the Commission, or employee of such contractor prepares, disseminates, or provides access to, any informatlon pursuant to his employment or contract with the Commlsuiurt, or hls employment with such contractor.

THE DOW CHEMICAL COMPANY ROCKY FLATS DIVISION

P. O. BOX 888

GOLDEN, COLORADO 80401

U. S. ATOMIC ENERGY COMMISSION

CONTRACT AT(29-1)-1106 


\section{ONTENTS}

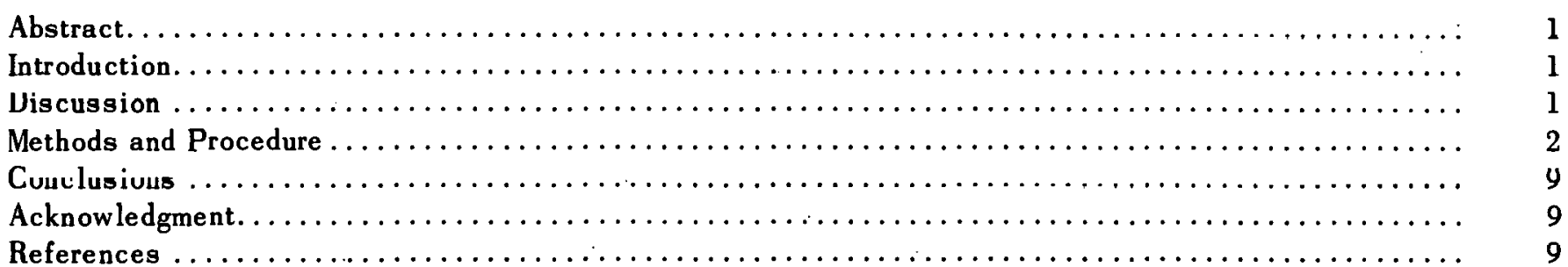




\title{
Mounting Materials and Alumina for Edge Retention in Preparing Metallographic Specimens
}

\author{
A. E. Calabra
}

\begin{abstract}
Excellent edge retention can be maintained on metallographic specimens by the addition of Coors Pelletized Alumina Mounting Filler to metallographic mounting materials. By this addition to the mounting material, specimen preparation, which previously had been extremely difficult, has now become routine.
\end{abstract}

\section{INTRODUCTION}

There are five basic requirements for a good metallographic-specimen mounting (or potting) compound. They are:

1. It must have approximately the same abrasive resistance as the abrasive resistance of the specimen. This is necessary to maintain satisfactory edge retention.

2. It must have minimal shrinkage during curing.

3. It must adapt to the shape of the specimen without causing damage to the specimen.

4. The curing temperature of the mounting compound should be low to prevent curing stresses which damage the specimen, or cause changes in the structural characteristics of the specimen.

5. It must be chemically inert to the polishing and etching solutions.

There is no potting compound which alone can fulfill all of the basic requirements. The purpose of this report is to describe several methods which will customize a mixture, using Coors Pelletized Alumina Mounting Filler (1) and various mounting materials, to the particular metallographic specimen. The result is a mount which will fulfill all of the basic requirements of a good mounting media.

\section{DISCUSSION}

Five metallographic specimen mounting methods are described which will customize the mounting medium to the sample, resulting in excellent retention of the specimen edge.
Method A. Vacuum casting a mixture of pelletized alumina filler and Maraset (2) epoxy resin.

Method B. Pelletized alumina filler and a selfcuring, polyester resin mixture.

Method C. Pelletized alumina filler and a self-curing, short-curing time, epoxy resin mixture.

Method D. Pelletized alumina filler and a thermoplastic resin mixture.

Method E. Pelletized alumina filler and a thermosetting resin mixture.

The mounting materials available and in use by metallography laboratories are so numerous that it is impossible to discuss all of them in this report. However, the techniques described can be a guide to the laboratory technician, and with a minimum of experimentation the Coors Pelletized Alumina Mounting Filler can be used with any available mounting medium.

The Coors Pelletized Alumina $\left(\mathrm{Al}_{2} \mathrm{O}_{3}\right)$ Filler is available in mesh sizes of -80 to +250 and -250 mesh (Standard Tyler). The -250 mesh is recommended for the complex-shaped specimens. The larger -80 to +250 mesh is recommended for the regular-shaped metallographic samples.

The alumina hardness grades are low-, medium-, and high-fired. For soft metals the soft, low-fired alumina is recommended. The medium-fired, medium hard alumina, is adaptable to the medium-hard materials, e.g., cast irons, soft steels and many non-ferrous metals and alloys. The high-fired, hard alumina, is used for the hard, and hardened, materials.

Each alumina body is slightly cup-shaped with a semi-rough surface and a "raspberry" configuration (see Figure 1). Because of this configuration, it readily adheres to the mounting medium and eliminates the problem of the alumina body tearing loose from the matrix and scratching the specimen during preparation. 


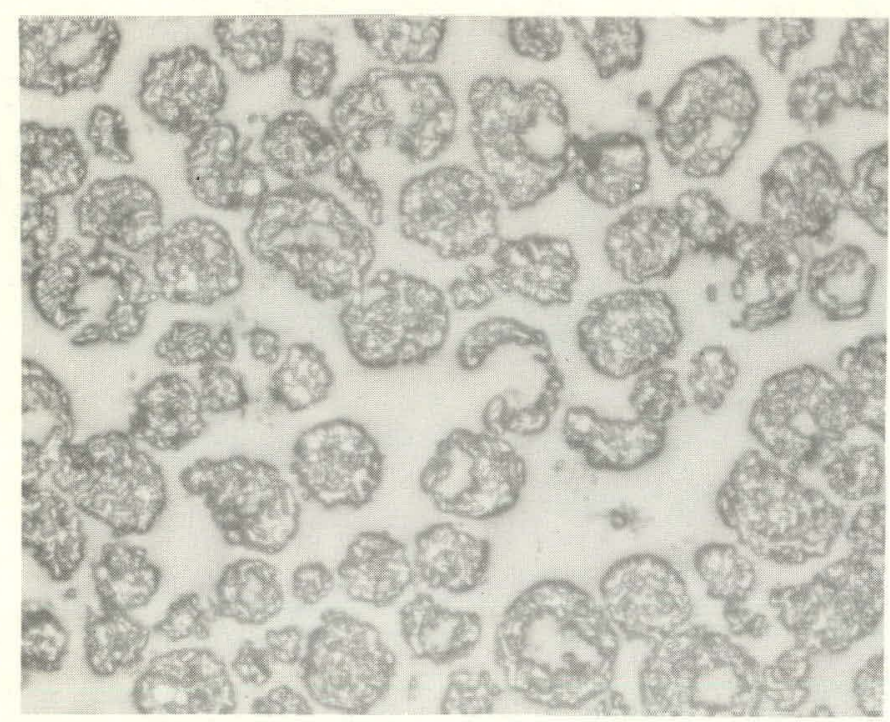

Figure 1. Coors Mounting Filler Pelletized Alumina bodies in Maraset based matrix. (-250 mesh) 200X Bright Field.

An important feature of the mixture of alumina and mounting material is the negligible mold-shrinkage which occurs during curing. This is attributed to the configuration of the alumina body (see Figure 1). Each alumina body acts to effect a uniform shrinkage throughout the mounting medium and prevents a high cumulative shrinkage from occurring adjacent to the metallographic sample. By minimizing or eliminating the shrinkage adjacent to the sample, the space where sample preparation liquids can accumulate is minimized or eliminated. Staining will normally occur when solutions exude from this space onto the sample. Also, as a result of eliminating the local shrinkage, abnormal stresses on the sample are avoided. These stresses, if not compensated for, can damage delicate metallographic specimens (3).

The grinding and polishing, of samples mounted by the various methods described, require additional care beyond that required for samples mounted by conventional methods. Because the mount has been customized to the metallographic specimen, the entire mount-surface is abrasion resistant and the silicon-carbide-grit grinding papers wear rapidly. Consequently, during each step, the grinding papers must be changed more frequently than normal. The experienced technician can tell by "feel"' when the grinding paper is no longer cutting. There is danger of introducing abnormally disturbed metal if the technician presses too hard on the mounted specimen, or if he is using worn grinding papers. Polishing will take several minutes longer than is normally required for samples mounted in conventional mounting materials. However, the extra care and time taken during sample preparation is justified because of the superior metallographic results.

Specific grinding and polishing techniques vary; therefore, no preparation details will be given in this report. It is believed that the Coors Mounting Filler and mounting compound mixtures are amenable to techniques used in any metallography laboratories.

\section{METHODS AND PROCEDURE}

Method A. Vacuum casting a mixture of Coors Pelletized Alumina Filler and Maraset (2) epoxy resin.

The mixture of Coors Mounting Filler and Maraset epoxy resin, prepared and cured under vacuum, is the most versatile and efficient of all metallographic mounting media used in the Metallography Laboratories at Rocky Flats.

Maraset is a brand name for a two-part epoxy resin which cures in approximately 12 hours at $65^{\circ} \mathrm{C}$ and requires no pressure. A very important feature is that at $65^{\circ} \mathrm{C}$ it will become fluid and will remain fluid for approximately one hour. During this time of high fluidity, the alumina and Maraset mixture and specimen can be outgassed for the mounting of samples with intricate shapes where voids, holes, tubes, cracks, and/or convolutes must be filled. Also, because no pressure is necessary, delicate samples or thin sections can be mounted without damage.

Each metallographic specimen is mounted in a reusable precast Silastic RTV 501 (4) silicone rubbermold. For general metallographic requirements the mold is made with a cavity one inch to $1 \frac{1}{4}$-inches in diameter by $1 \frac{1}{3}$-inches deep. Figure 2 shows the. breakaway master-mold in which the silicone rubber-mold is cast.

The specimen is placed in the mold, and the Maraset and alumina mixturc (which is preheated to approximately $65^{\circ} \mathrm{C}$ ) is poured into the mold. The alumina hardness and mesh size must be matched to the sample hardness and configuration, or to other metallographic requirements. The amount of filler material added will depend upon the amount of material which 

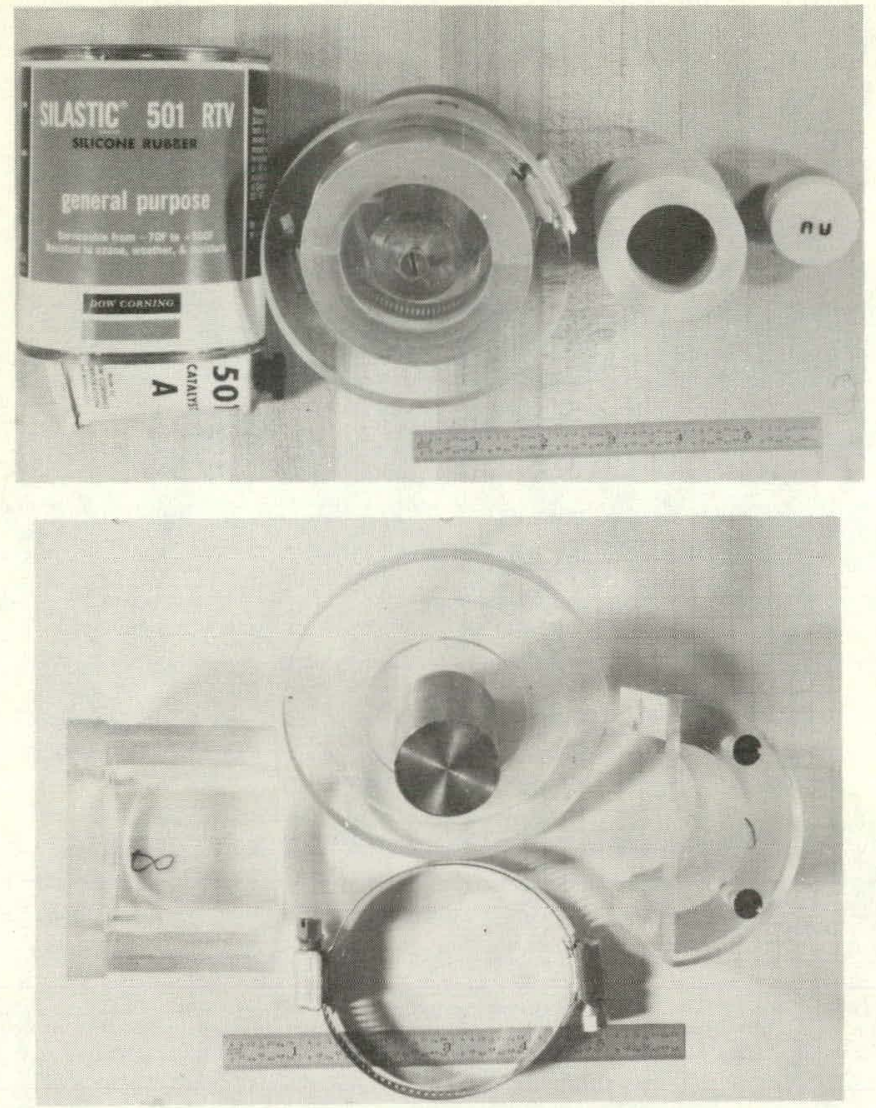

Figure 2. Upper - Dow corning silastic RTV 501 silicone rubber compound, the master mold, a cured silicone rubber mold, and a mounted sample. Lower - Component parts of the breakaway master mold. Plexiglas based mold with a stainless steel plug and steel hose clamp.

must be removed from the specimen in order to reveal the desired plane of examination. The mount should have at least one-quarter-inch of pelletized alumina remaining after the sample has been ground and polished.

The mold is then placed in the preheated vacuumoven set at approximately $65^{\circ} \mathrm{C}$ and it is then outgassed. This outgassing ensures complete wetting of the alumina bodies and the specimen surfaces (see Figure 1). During the outgassing procedure, the epoxy vehicle carries the alumina bodies into the voids, holes, etc. in the metallographic specimen. The outgassing must be watched for a short time, and the vacuum controlled, because, during the initial outgassing, vigorous bubbling might occur and cause the material to overflow the mold cavity. The vacuum should be held to a level at which no overflowing occurs. When vigorous bubbling decreases, the mixture can be allowed to cure unattended. It is the practice of the laboratory to prepare the mounts during the work day and vacuum-oven cure overnight.

The inherent mold shrinkage in Maraset is relatively small, and with the addition of the pelletized alumina, and the $65^{\circ} \mathrm{C}$ curing temperature, the curing shrinkage is minimal. Staining, by the exuding of solution from between the mount material and specimen, is no longer a problem. There also has been no evidence of specimen damage due to curing stresses when cured under vacuum at $65^{\circ} \mathrm{C}$.

No polishing and/or etching solutions used have attacked the alumina and Maraset mixture. However prolonged contact with acetone or alcohol will soften the surface of the mount.

Maraset can be made up in a quantity for laboratory use and can then be stored under refrigeration for several weeks.

Figures 3 through 7 are photomicrographs of metallographic specimens prepared using the mixture of Coors Mounting Filler and Maraset epoxy resin. Note the excellent edge retention and specimen flatness on the various metals as a result of matching

Figure 3. High purity annealed silver. Mounted in Marasetlow fired Coors Mounting Filler (-250 mesh) mixture. Etchant: $\mathrm{K}_{2} \mathrm{Cr}_{2} \mathrm{O}_{7}-\mathrm{NaCl}-\mathrm{H}_{2} \mathrm{SO}_{4}$ aqueous solution. 120X Bright Field

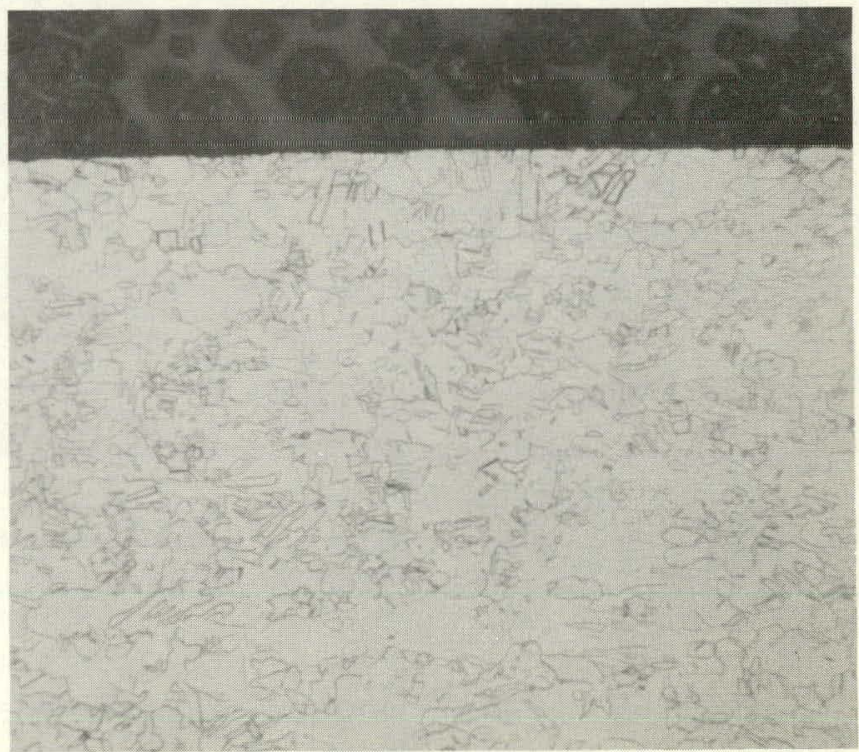




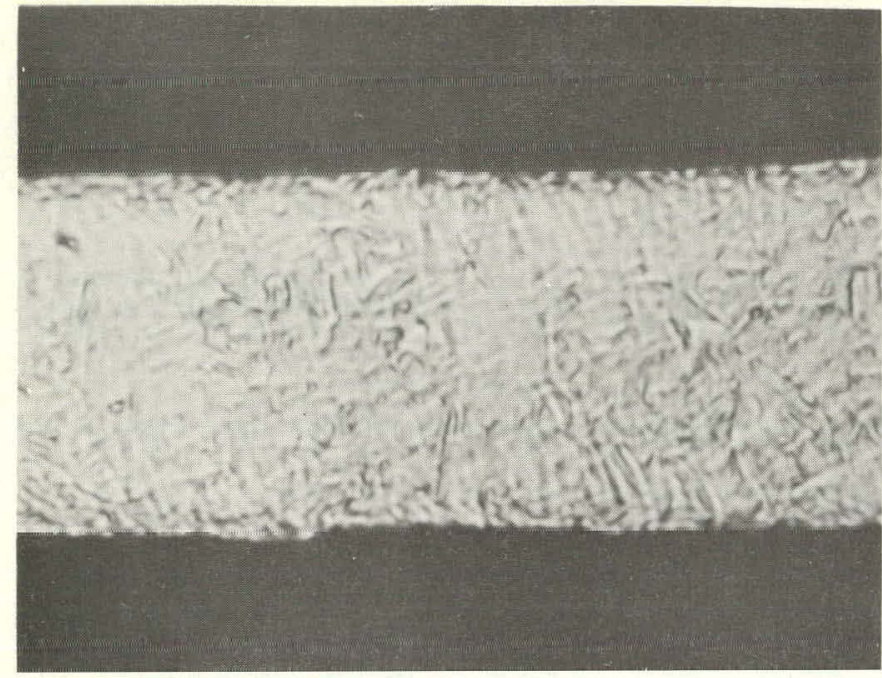

Figure 4. Vapor deposited copper - 0.0007-inch thick. Maraset-low fired mounting filler $(-80+250$ mesh $)$ mixture. Etchant: $\mathrm{NH}_{4} \mathrm{OH} \cdot \mathrm{NaOH}-\mathrm{H}_{2} \mathrm{O}_{2}$ aqueous solution. 2000X Bright Field

Figure 5. Stainless steel tubing - 304 type; 0.008-inch outside diameter, 0.004-inch inside diameter, as drawn. Hardness: Rockwell $15 \mathrm{~T}=80$. Marasetmedium fired Coors Mounting Filler (-250 mesh). Etchant: $10 \%$ oxalic acid 325X Polarized Light

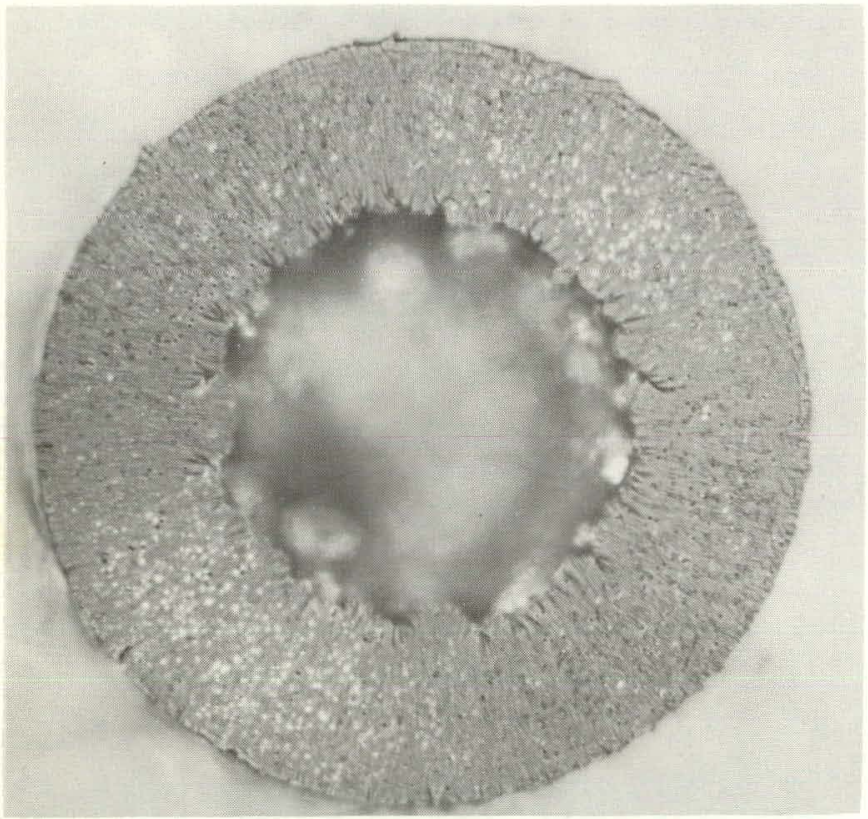

the alumina hardness and mesh size to the metallographic specimen. The soft silver and vapor-deposited copper would have been extremely difficult to resolve had it not been mounted by the described procedure. The metallographic preparation of the stainless steel

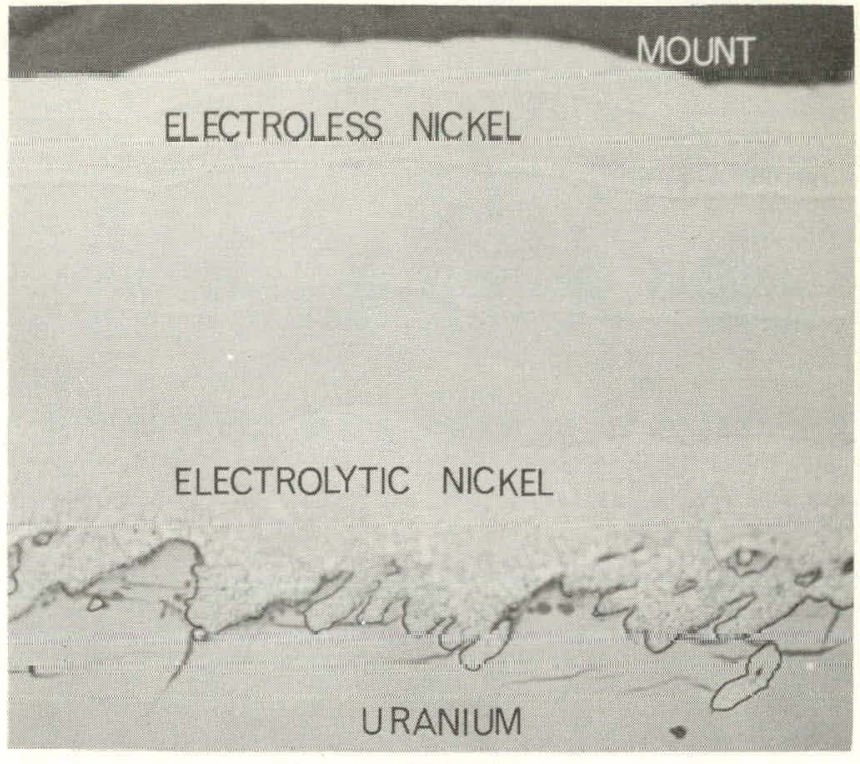

Figure 6. Electrolytic-electroless nickel plated on uranium. Maraset-medium fired filler $(-80+250$ mesh $)$. Etchant: As-polished in chromic acid-gamma alumina slurry.

500X Bright Field

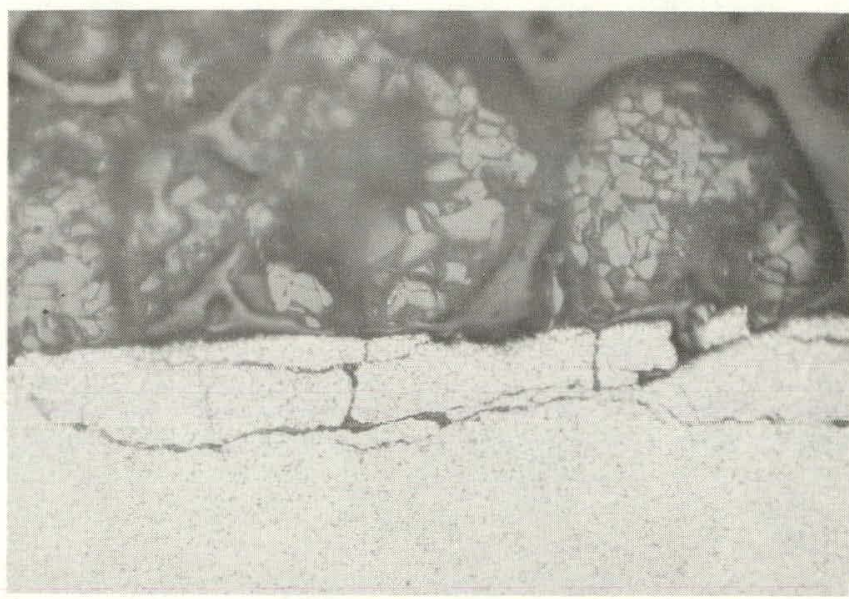

Figure 7. Tungsten Carbide Machine Tool. Harness Rockwell C 52. Maraset high fired Coors Mounting Filler mixture $(-80+250$ mesh). Etchant: As-polished in ehromic acid-gamma alumina slurry. 300X Bright Field

tube shown in Figure 5, because of its minuteness (0.008-inch OD by 0.004 -inch ID), would be virtually impossible without this technique. The edge retention of the plated specimen (Figure 6) was readily obtained using the medium-fired alumina. The edge preservation on very hard metals can also readily be obtained using the high-fired or hard alumina (Figure 7). The space between the mounting medium and metallographic specimen is no longer present. 
Method B. Pelletized alumina filler and a self-curing polyester resin mixture.

The self-curing polyester resin used in the metallography laboratory is Fiberlay Clear-Cast (5) brand (liquid plus catalyst) which requires approximately 8 hours .curing time.

There are three characteristics of this polyester resin which make it an ideal mounting medium and binder for the pelletized alumina. They are:

1. Low exothermic curing temperature, approximately $36^{\circ} \mathrm{C}$, which results in minimal curing stresses. This feature makes it ideal for very delicate samples and for metals which will transfunm at low temperatures.

2. The alumina-resin mixture has negligible shrinkage, resulting in almost no separation between the mold material and specimen. Because of this, the troublesome staining by the preparation solutions exuding from space between the mount and sample is virtually eliminated.

3. 'I'he C'lear Liast polyester resin has a lluid cousistency such that each alumina body can be completely wet, leaving little danger of the particle pulling out and scratching the specimen during preparation. Also, entrapped bubbles tend to rise during curing and this leaves a porousfree surface.

The mixing procedure, for a 1 -inch diameter mount, is as follows:

$10 \mathrm{ml}$ Fiberlay Clear-Cast

2 drops Catalyst (P102)

5 cc Coors Alumina Mounting Filler;

hardness and mesh size matched to the metallography sample.

Curing time - approximately 8 hours.

Slowly pour in the alumina while gently stirring the mixture. Pour the mixture into the silicone rubber mold containing the specimen.

Figure 8 shows the alumina particles in the ClearCast binder. Each alumina body appears completely wet and this results in a porous-free surface. Figure 9 is a photomicrograph of a tungsten-metallographic specimen. Edge retention is maintained with negligible shrinkage of the mounting medium from the sample.

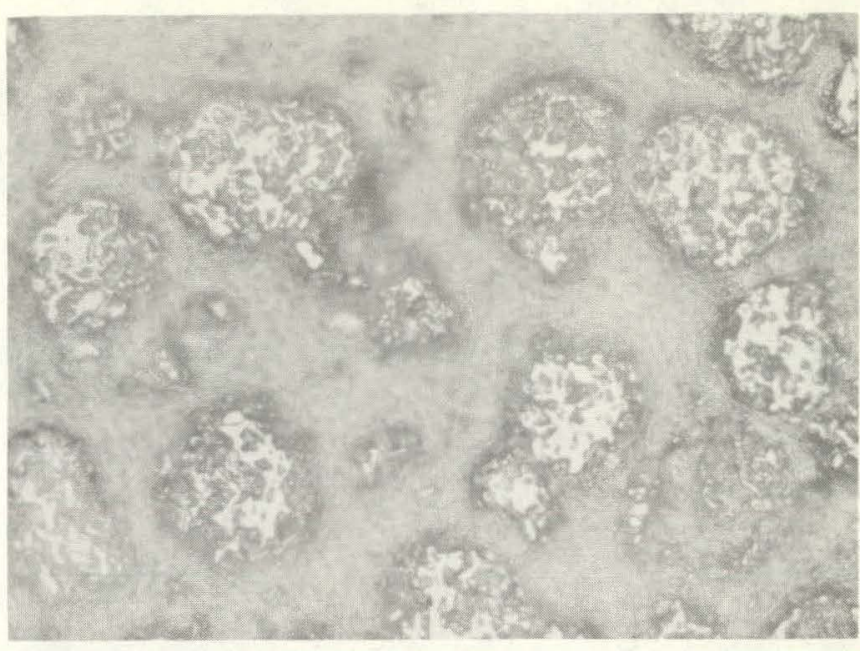

Figure 8. Mixture of Coors Mounting Filler (-250 mesh) and Fiberlay Clear-Cast brand Mounting Polyester. Each alumina body appears to be wet by the mounting media resulting in a porous-free surface.

250X Bright Field

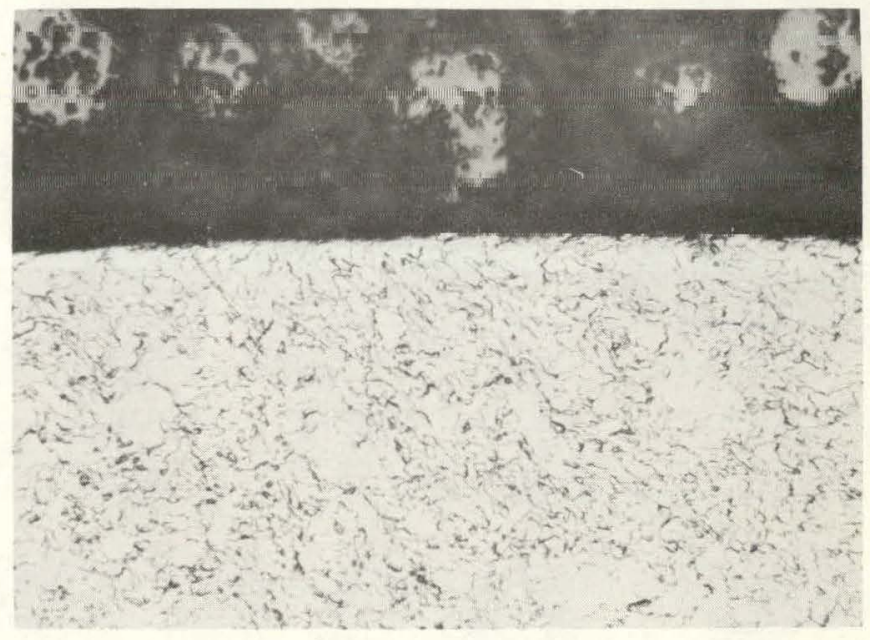

Figure 9. Tungsten. Hardness Rockwell C 45. Mounted in Coors Mounting Filler (-250 mesh high fired) and self curing polyester mixture. Etchant: Murakami's Reagent.

250X Bright Field

This mounting procedure is extremely helpful in the glove box metallography facilities at Rocky Flats where staining has been troublesome and time consuming to remove. It is ideal for facilities where vacuum casting (Method A) cannot be incorporated.

Fiberlay Clear-Cast polyester resin is normally not affected by polishing and/or etching solutions. Prolonged contact with carbon tetrachloride does not affect the mounting medium. However, long contact with acetone and alcohol will soften the surface. 
For the technician who must provide relatively "quick" metallography and still have specimen edge retention, Coors Mounting Filler can be used with either a short curing time, self-curing epoxy resin (Method C), a thermoplastic resin (Method D), or thermosetting resins (Method E). These mixtures are ideal for the regular-shaped metallographic samples. They are not recommended, however, for delicate samples or for those requiring impregnation of cracks, voids, holes, tubes, and/or convolutes.

No outgassing is normally performed on these mixtures and, therefore, a slightly porous mount-surface results (see Figure 10). The mounted sample must be cleaned carefully, preferably in an ultrasonic cleaner, between each preparation step.

Each alumina body is sufficiently wet by the mounting medium so that there is little danger of it dislodging and scratching the sample during preparation (see Figure 11).

Method C. Coors Pelletized Alumina Filler and a short curing time, self-curing epoxy resin mixture.

This laboratory uses both Koldmount (6) and Quickmount (7) brands as short curing time, self-curing resins. They consist of two parts; a powdered resin and a liquid hardener, and they normally cure in less than 45 minutes. The exothermic curing temperature is determined to be approximately $100^{\circ} \mathrm{C}$.

The mixing procedure for Method $\mathrm{C}$ is as follows:

3 parts self-curing epoxy resin powder

4 parts liquid hardener

4 parts Coors Mounting Filler of selected hardness and mesh size

Curing time - approximately 45 minutes

Mix the powder with the liquid hardener. Then slowly pour in the alumina while gently stirring the mixture. Continue to stir for one additional minute.

The specimen can be potted in the previously described silicone rubber mold.

Figure 11 is a representative photomicrograph showing the excellent edge retention and small edge-cracks on a tungsten specimen. High-fired (hard) Coors Mounting Filler was used with the self-curing resin.
This mixture is extremely useful where metallography is performed in glove boxes, and when the longer curing times cannot be tolerated; but only for specimens which will not be affected by the high $\left(100^{\circ} \mathrm{C}\right)$ curing temperature.

The self-curing resin is normally not affected by polishing and etching solutions. However, prolonged contact with acetone or alcohol will soften the mount surface. Carbon tetrachloride does not appear to affect it.

Method D. Coors Pelletized Alumina Filler and a thermoplastic resin mixture.

The thermoplastic mounting media is transoptic powder (8) which cures at approximately $4200 \mathrm{psi}$ and $140-150^{\circ} \mathrm{C}$ in a laboratory metallographic mounting press. The transoptic remains molten at the molding temperature and therefore necessitates cooling the mold below $60^{\circ} \mathrm{C}$ prior to removal from the mount press. The cured mold, without the alumina, is clear.

The mixing procedure for Method D is as follows:

7 parts transoptic powder

10 parts Coors Mounting Filler, matched in hardness and mesh size to the metallographic requirements.

Mix the powder and alumina thoroughly and pour into the preos mold cavity. The àmuuul of mixture will be determined by the amount of material which must be removed from the sample to reveal the plane of examination. An excess should be added such that at least one-quarter-inch of alumina mixture should remain in the mount after grinding and polishing. The remainder of the press mold cavity is then filled with transoptic powder.

Figure 12 shows the excellent edge retention, and the resolution of small cracks, obtained by the use of this procedure.

Method E. Coors Pelletized Alumina Filler and a thermosetting resin mixture.

The mounting media used as the vehicles for the Coors Mounting Filler are Bakelite (8), and diallyl phthalate filled with short glass fibers (8). In both materials, with the alumina 


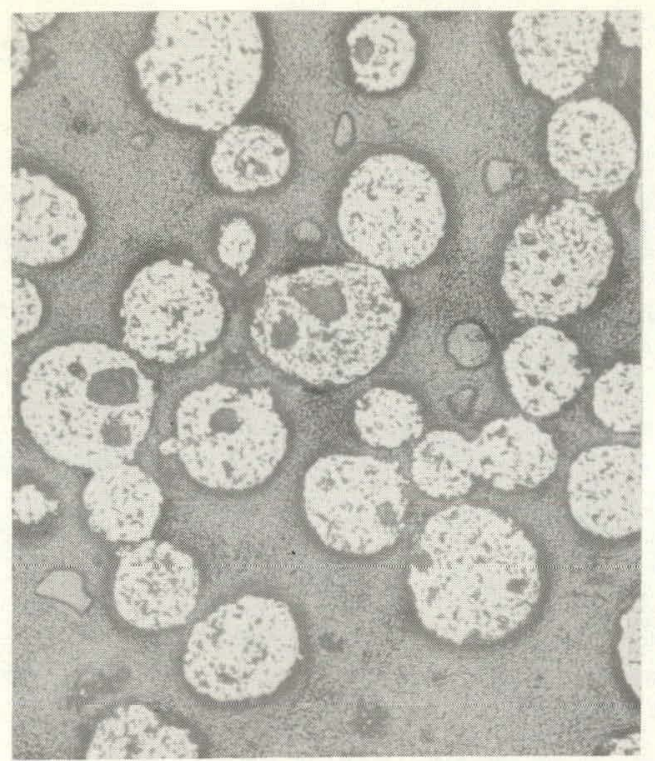

(a) Coors Mounting Filler - self-curing resin (Method C)

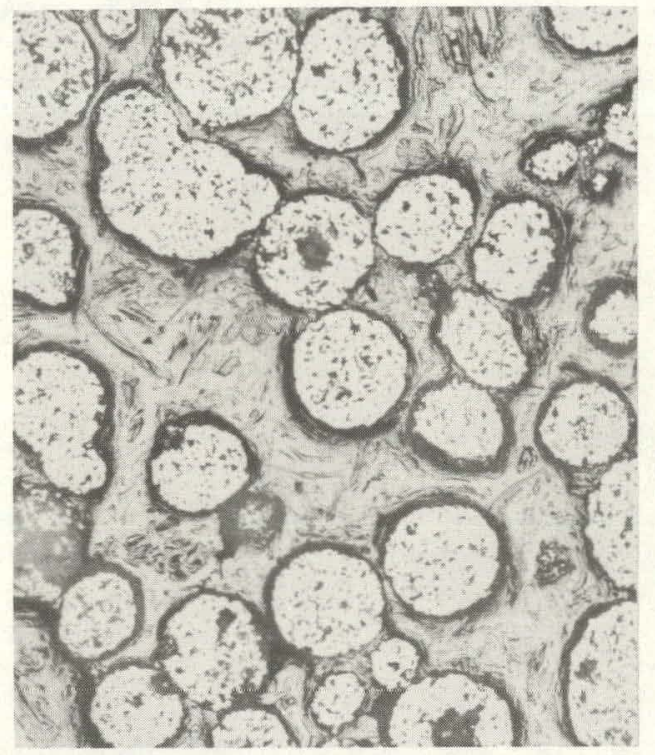

(c) Coors Mounting Filler - thermosetting resin, Bakelite (Method E)

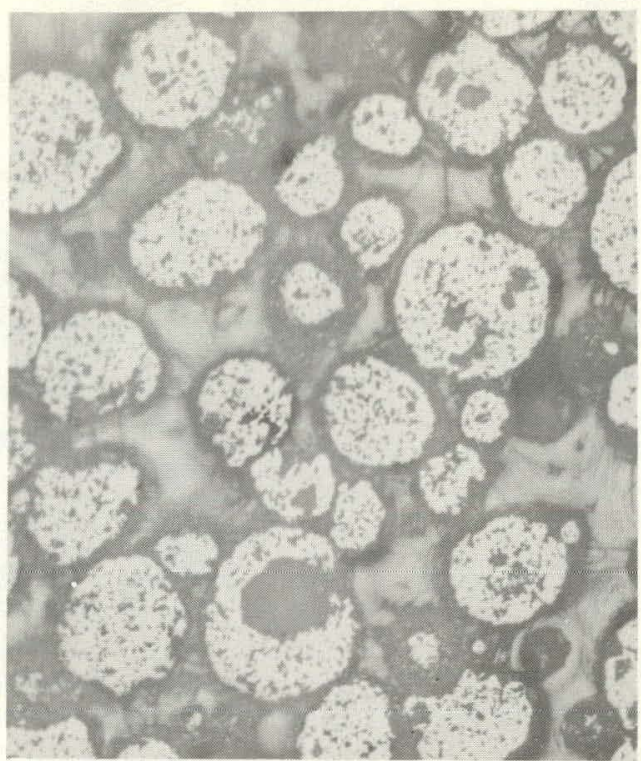

(b) Coors Mounting Filler - thermoplastic resin, transoptic (Method D)

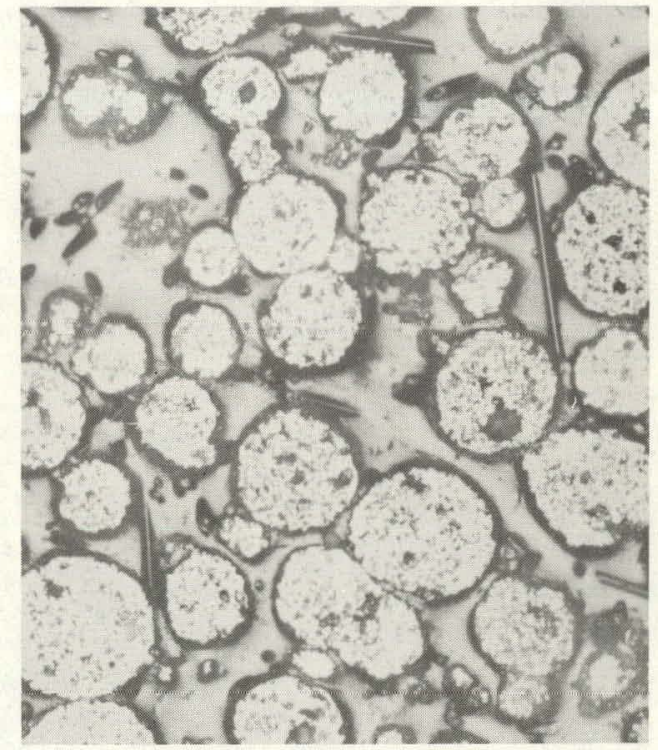

(d) Coors Mounting Filler - thermosetting resin, diallyl phthalate (Method E)

Figure 10. Mixtures of the Cloors Mounting Filler and Mounting Medias. 100X 


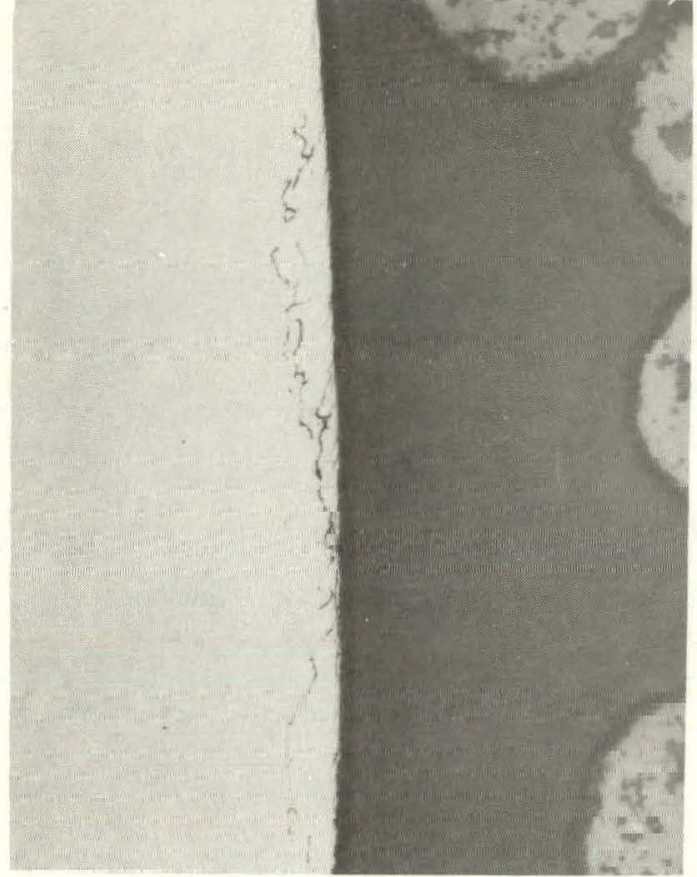

Figure 11. Tungsten with edge cracks. Hardness Rockwell C 45. Coors Mounting Filler $(-80+250$ mesh, high fired) and self-curing resin mixture. Etchant: As-polished in chromic acid - gamma alumina slurry.

100X Bright Field

Figure 13. Tungsten with edge crack. Hardness Rockwell C 45. Coors Mounting Filler $(-80+250$ mesh, high fired) and Bakelite based mixture. Etchant: Murakani's Reagent.

80X Bright Field

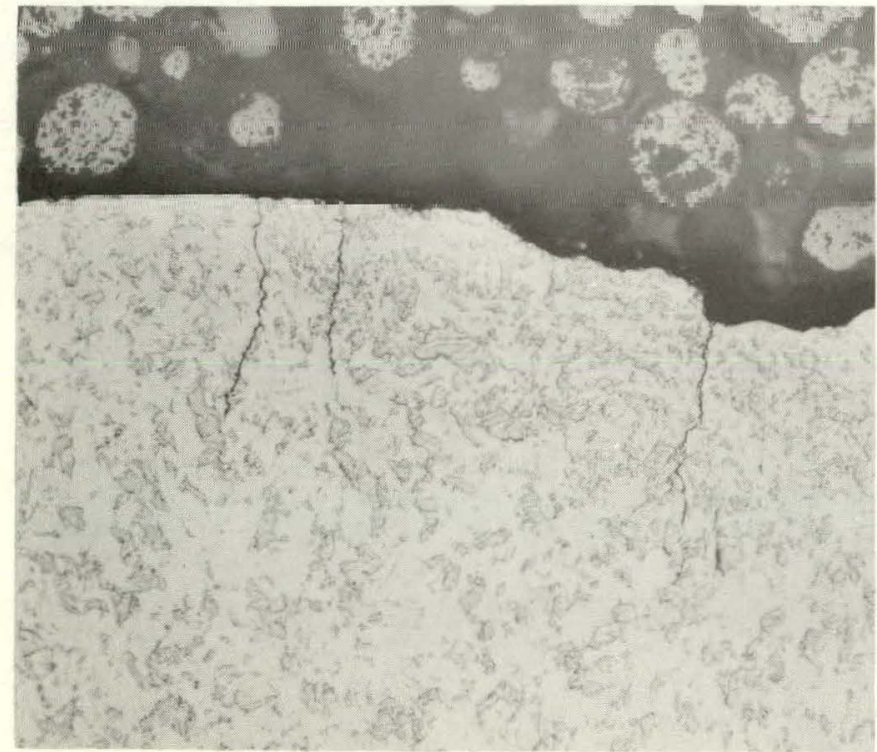

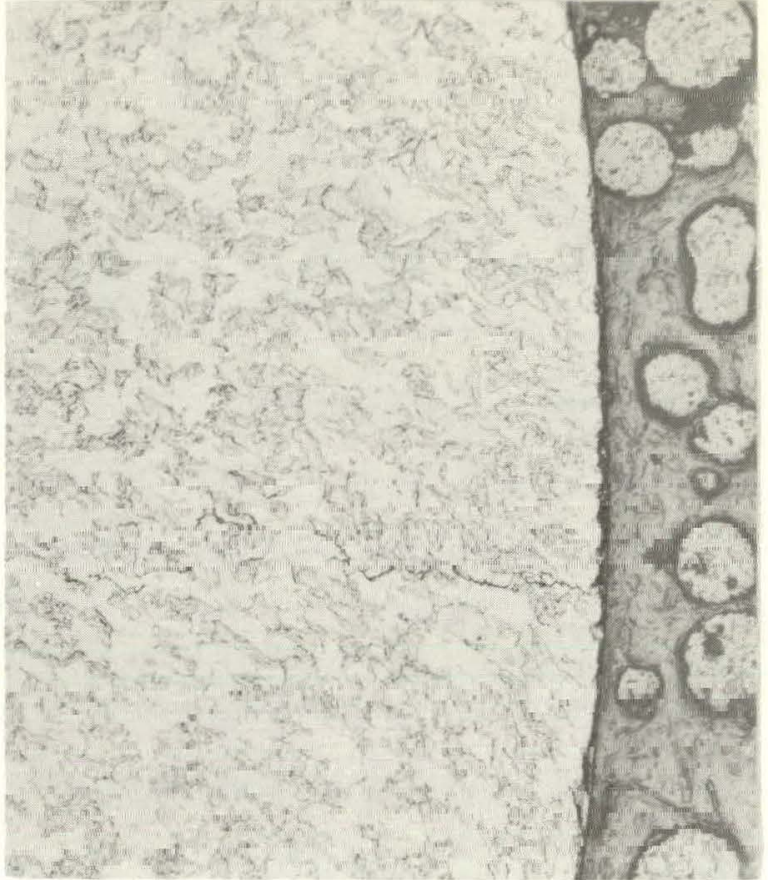

Figure 12. Tungsten with edge eracks. Hardness Rockwell C 45. Coors Mounting Filler $(-80+250$ mesh, high fired) and transoptic mixture. Etchant: Murakami's Reagent. 80X Bright Field

Figure 14. Tungsten. Hardness Rockwell C 45. Coors Mounting Filler $(-80+250$ mesh $)$ and diallyl phthalate mixture. Etchant: Murakami's Reagent. $\quad$ BUX Bright Field

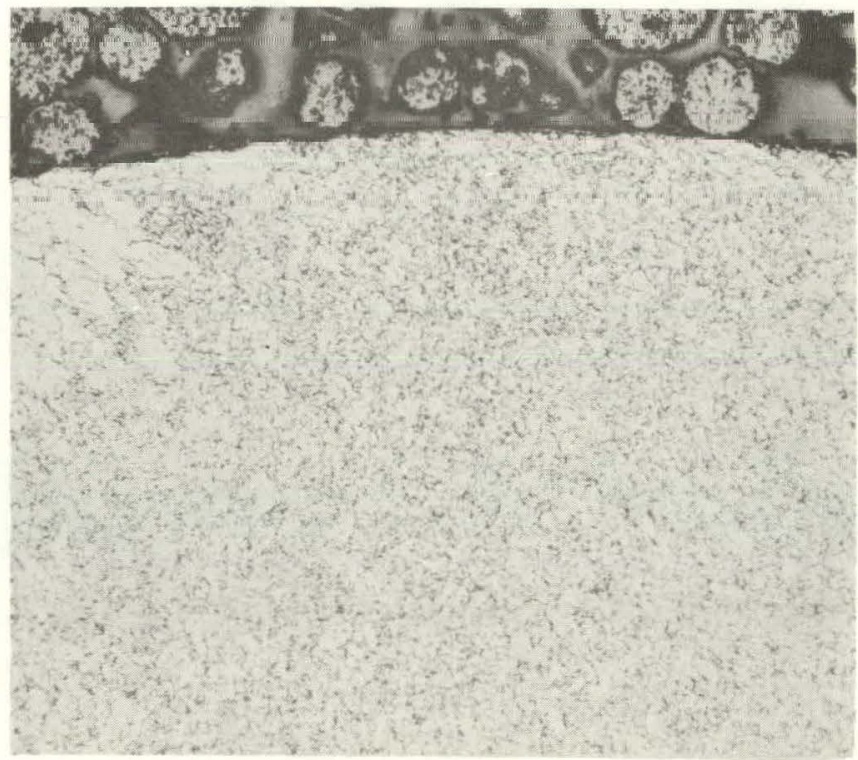


filler added, excellent edge retention is maintained. See Figures 13 and 14.

Bakelite and diallyl phthalate are thermosetting, requiring heat and pressure during the molding cycle, and may be ejected from the mounting press at the maximum molding temperature.

The mixing procedures are as follows:

1. Bakelite mixture

1 part Bakelite crushed to -150 mesh

1 part Coors Mounting Filler, matched in hardness and mesh size to the metallographic requirements.

\section{Diallyl phthalate}

1 part crushed diallyl phthalate (glass filled) 1 part Coors Mounting Filler, matched to the metallographic sample.

Crushing of the Bakelite and diallyl phthalate can be done with a mortar and pestle or a laboratory blender-mill. The amount of mixture is dependent on the depth to which metal must be removed to reveal the specimen plane of examination plus the one-quarter-inch excess. The remainder of the mold cavity is filled with the uncrushed Bakelite or diallyl phthalate.

\section{CONCLUSIONS}

1. Coors Mounting Filler mixed with the described mounting compounds fulfill the requirements of good metallographic specimen mounting media.

2. The use of alumina with various hardnesses and particle sizes in combination with different mounting compounds provides the laboratory with the capability of customizing mounting media to the metallographic sample.

3. The techniques described are amenable to any mounting material or techniques used in metallography laboratories.

4. Excellent sample flatness and edge retention can be obtained on soft or hard materials.
5. Mold curing shrinkage is minimal with the alumina and mounting medium mixtures.

6. Metallography that in the past has been extremely difficult now has become routine by the addition of Coors Mounting Filler to the mounting compound.

\section{.ACKNOWLEDGMENT}

The author expresses gratitude to Mr. Tony J. LaRocco, Research Engineer, Coors Porcelain Company who, in response to a need for a mounting filler which would be versatile and fulfill the various requirements of the Metallographic Laboratory, suggested the alumina marketed as Coors Mounting Filler.

\section{REFERENCES}

1. Coors Mounting Filler; Coors Porcelain Company, 600 9th Street, Golden, Colorado 80401.

2. Maraset epoxy resin; Maraglas Type A, formerly resin 655/555 hardener; Marblette Corporation, 37-31 30th Street, Long Island City, New York.

3. "An Effect of Curing Stresses in Epoxy Resins," R. C. Crouse and R. J. Gray, Oak Ridge National Laboratory, Oak Ridge, Tennessee; published in Advances in Metallography, edited by R. J. Jackson and A. E. Calabra; The Dow Chemical Company, Rocky Flats Division, Golden, Colorado 80401. RFP-658.

4. Silastic RTV 501 with Catalyst A; The Dow Corning Corporation, Midland, Michigan.

5. Fiberlay Clear-Cast resin with catalyst P102; Fiberlay, Incorporated, 1158 Fairview, Seattle, Washington 98109.

6. Koldmount mounting resin; Vernon-Bensh off Company, Inc., Subsidiary of CMP Industries, Inc., Box 350, Albany, New York 12201.

7. Quickmount mounting resin; Fulton Metallurgical Products Corporation, 4716 Ellsworth Avenue, Pittsburgh, Pennsylvania 15213.

8. Transoptic Powder, Bakelite, and diallyl phthalate; Adolph I. Buehler, Inc., 2120 Greenwood Street, Evanston, Illinois. 